\title{
Rapid lymphatic efflux limits cerebrospinal fluid flow to the brain
}

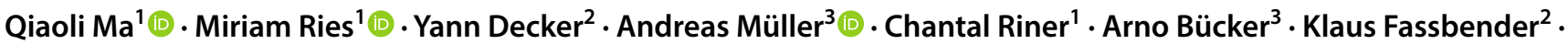 \\ Michael Detmar ${ }^{1} \cdot$ Steven T. Proulx ${ }^{1}$ (1)
}

Received: 17 August 2018 / Revised: 25 September 2018 / Accepted: 26 September 2018 / Published online: 10 October 2018

(c) The Author(s) 2018

\begin{abstract}
The relationships between cerebrospinal fluid (CSF) and brain interstitial fluid are still being elucidated. It has been proposed that CSF within the subarachnoid space will enter paravascular spaces along arteries to flush through the parenchyma of the brain. However, CSF also directly exits the subarachnoid space through the cribriform plate and other perineural routes to reach the lymphatic system. In this study, we aimed to elucidate the functional relationship between CSF efflux through lymphatics and the potential influx into the brain by assessment of the distribution of CSF-infused tracers in awake and anesthetized mice. Using near-infrared fluorescence imaging, we showed that tracers quickly exited the subarachnoid space by transport through the lymphatic system to the systemic circulation in awake mice, significantly limiting their spread to the paravascular spaces of the brain. Magnetic resonance imaging and fluorescence microscopy through the skull under anesthetized conditions indicated that tracers remained confined to paravascular spaces on the surface of the brain. Immediately after death, a substantial influx of tracers occurred along paravascular spaces extending into the brain parenchyma. We conclude that under normal conditions a rapid CSF turnover through lymphatics precludes significant bulk flow into the brain.
\end{abstract}

Keywords Cerebrospinal fluid · Lymphatic vessel · Paravascular space · Anesthesia

\section{Introduction}

The anatomical pathways and physiological mechanisms for the production, circulation and absorption of cerebrospinal fluid (CSF) and brain interstitial fluid (ISF) are currently an area of intense research focus. Historically, ISF is considered to be produced at the blood-brain barrier and to drain out of the brain towards the CSF [1, 14, 24, 53]. Pathways for a bulk flow of ISF from the brain parenchyma were found to be along peri-(or para-) vascular spaces (PVS) to reach the

Electronic supplementary material The online version of this article (https://doi.org/10.1007/s00401-018-1916-x) contains supplementary material, which is available to authorized users.

Steven T. Proulx

steven.proulx@pharma.ethz.ch

1 Institute of Pharmaceutical Sciences, Swiss Federal Institute of Technology, ETH Zurich, Vladimir-Prelog-Weg 1-5/10, HCI H398, 8093 Zurich, Switzerland

2 Department of Neurology, University of the Saarland, 66421 Homburg, Saar, Germany

3 Clinic for Diagnostic and Interventional Radiology, Saarland University Medical Center, 66421 Homburg, Saar, Germany subarachnoid space (SAS) [13, 24, 53, 57] or along white matter fiber tracts to reach the ventricles [13, 46, 48]. However, several reports were published that ran counter to this view and suggested that a flow of CSF could occur from the SAS into the brain $[8,11,40,45,52]$. Of special note, Rennels et al. proposed a rapid CSF microcirculation to the brain with paravascular influx around arteries and efflux along veins. Although this concept was not fully accepted at the time [27], this work was recently cited as supporting evidence for a proposed glymphatic system of flow by Iliff et al. [29]. In experimental studies, tracers injected into the cisterna magna in mice were found with 2-photon imaging through a cranial window to enter the PVS around arteries penetrating into the cortex. At later time points tracers were also present in the PVS around veins. It was proposed that an astrocyte-facilitated convective flow existed through the parenchyma with influx along arteries and efflux along veins. Interestingly, this system was found to be more active during sleeping or anesthetized conditions compared to awake conditions [54]. However, at this time, these studies remain highly controversial and several groups have challenged various aspects of the concept $[1,3,5,19,21,25,26,50,51]$. 
While it is traditionally understood that CSF is absorbed mostly through arachnoid projections into the venous blood, we have recently demonstrated, using in vivo dynamic fluorescence imaging, that bulk outflow of CSF occurs predominantly through the lymphatic system in mice [37]. The major CSF outflow pathways were found along cranial nerves (e.g., olfactory and optic) to reach lymphatic vessels outside the skull, consistent with many previous reports $[10,32,33$, 39]. We have also demonstrated that lymphatic transport of interstitial fluid from skin and the peritoneal cavity is vastly increased during awake conditions compared to anesthetized conditions [44]. Therefore, it is of interest to determine how CSF outflow differs between awake and anesthetized mice and how these potential differences could influence the spread of CSF to the PVS of the brain. Thus, the first aim of the current study was to assess how lymphatic outflow from the CSF to the systemic blood is altered during awake conditions compared to anesthetized conditions. We next aimed to determine whether the outflow of CSF was correlated with the spread of tracers from the CSF into the PVS of the brain surface and brain parenchyma. Finally, we attempted to confirm whether an influx of tracers through the arterial PVS could be demonstrated under in vivo anesthetized conditions using through-skull near-infrared (NIR) imaging or by magnetic resonance imaging (MRI).

\section{Materials and methods}

\section{Mice}

Female C57BL/6J-Tyr ${ }^{c-J}$ albino or C57BL/6J wild type mice (Jackson Laboratories, Bar Harbor, ME) and Prox 1-GFP [12] and SMMHC-GFP [55] reporter mice on C57BL/6J backgrounds were kept under specific pathogen-free conditions and used for experimental studies at the age of 2-3 months. All mouse experiments were approved by Kantonales Veterinaramt Zurich (license numbers 185/13, 196/13 and 161/16) and by the Landesamt für Gesundheit und Verbraucherschutz, Saarbruecken, Germany (license number: 15/2017), and performed following the regulations of the Swiss Federal Welfare Act (TSchG) and the European legislation on the protection of animals (Directive 2010/63/ EU).

\section{Studies of CSF outflow during awake or anesthesia conditions}

At $20 \mathrm{~min}$ before intracerebroventricular (i.c.v.) infusion, $0.1 \mathrm{mg} / \mathrm{kg}$ buprenorphine was injected subcutaneously. Mice were anesthetized by intraperitoneal injection of $80 \mathrm{mg} / \mathrm{kg}$ ketamine and $0.2 \mathrm{mg} / \mathrm{kg}$ medetomidine or inhalation of $2 \%$ isoflurane and fixed in a stereotaxic frame (RWD, San Diego,
CA). For the awake group, lateral ventricle tracer infusion (as described below) was performed under $2 \%$ isoflurane and the mice were allowed to recover (within 5-10 min after infusion) and were awake for $60 \mathrm{~min}$ before imaging. Mice were observed to be active and behaving normally. For the isoflurane group, tracer infusion was performed under $2 \%$ isoflurane and the mice were kept anesthetized under $2 \%$ isoflurane for $60 \mathrm{~min}$ on a heating pad $\left(37^{\circ} \mathrm{C}\right)$ before imaging. For the ket/med group, $80 \mathrm{mg} / \mathrm{kg}$ ketamine and $0.2 \mathrm{mg} / \mathrm{kg}$ medetomidine were injected intraperitoneally before tracer infusion and the mice were kept anesthetized for $60 \mathrm{~min}$ on a heating pad $\left(37^{\circ} \mathrm{C}\right)$ before imaging. About $2 \mathrm{~min}$ before imaging at the saphenous vein, mice from the awake and isoflurane groups were given $80 \mathrm{mg} / \mathrm{kg}$ ketamine and $0.2 \mathrm{mg} /$ $\mathrm{kg}$ medetomidine intraperitoneally. Mice were first imaged for the blood signal at the saphenous vein, then overdosed by intraperitoneal injection of $400 \mathrm{mg} / \mathrm{kg}$ ketamine and $1 \mathrm{mg} /$ $\mathrm{kg}$ medetomidine for post-mortem imaging.

\section{Infusion of tracers into the lateral ventricle}

The skull was thinned with a dental drill (RWD) at a location $0.95 \mathrm{~mm}$ lateral and $0.22 \mathrm{~mm}$ caudal to the bregma. A $34 \mathrm{G}$ steel needle was inserted into the right lateral ventricle $2.35 \mathrm{~mm}$ ventral to the skull surface. For the standard protocol, $2.5 \mu \mathrm{L}$ of $200 \mu \mathrm{M}$ P40D680 or P40D800 [43] tracer at the speed of $1 \mu \mathrm{L} / \mathrm{min}$ was then infused with a syringe pump (Stoelting, Wood Dale, IL). For determination of the outflow dynamics in response to different volume infusions, alternate protocols involving $1.0 \mu \mathrm{L}$ of $500 \mu \mathrm{M}$ P40D680 at $0.4 \mu \mathrm{L} / \mathrm{min}$ and $5.0 \mu \mathrm{L}$ of $100 \mu \mathrm{M}$ P40D680 at $2 \mu \mathrm{L} / \mathrm{min}$ were used. The needle was left in place for $2.5 \mathrm{~min}$ and then slowly removed while observing if any significant backflow occurred. After tracer infusion, the injection hole in the skull was filled with bone wax (Ethicon, Somerville, NJ) and the scalp was sutured, except when in vivo throughskull imaging was subsequently carried out. Animals were excluded if significant backflow occurred or ex vivo analysis of brain slices indicated that the injection of tracer into the ventricle was not successful. For experiments where ventricular infusion was followed by dynamic contrast-enhanced MRI imaging, an identical protocol was used with the following modifications: $2.5 \mu \mathrm{L}$ of a Gadospin D solution at $25 \mathrm{mM}$ gadolinium (nanoPET Pharma GmbH, Germany) was infused instead of P40D680, a $33 \mathrm{G}$ steel needle was used in combination with a NanoJet syringe pump (Chemyx, Stafford, CT) and the needle was left in place after infusion for $5 \mathrm{~min}$.

\section{Infusion of tracers into the cisterna magna}

Mice were anesthetized by intraperitoneal injection of $80 \mathrm{mg} / \mathrm{kg}$ ketamine and $0.2 \mathrm{mg} / \mathrm{kg}$ medetomidine, fixed in 
a stereotaxic frame (Kopf, Tujunga, CA) and the body temperature was maintained at $37{ }^{\circ} \mathrm{C}$ using a heating pad. A surgical procedure to access the cisterna magna was performed [30]. After a small skin incision over the occipital bone/cervical spinal cord was made, the three covering muscle layers were carefully dissected under a stereomicroscope using fine forceps and scissors. A beveled glass capillary micropipette (Sutter instruments, Novato, CA, USA) with a diameter of $<60 \mu \mathrm{m}$ was made using a Sutter P97 Pipette puller (Sutter instruments) and was positioned perpendicular to the ear bars and advanced to penetrate the dura until resistance was overcome, indicating entry into the cisterna magna as previously described [2]. Overall, $5 \mu \mathrm{L}$ of a Gadospin D solution at $25 \mathrm{mM}$ gadolinium (nanoPET Pharma $\mathrm{GmbH}$ ) was infused at the speed of $1 \mu \mathrm{L} / \mathrm{min}$ with a NanoJet syringe pump (Chemyx). After the infusion, the micropipette was left in place for $10 \mathrm{~min}$ to avoid reflux. Following its withdrawal, the wound was closed.

\section{NIR imaging of CSF lymphatic transport to systemic blood}

For noninvasive imaging of tracer signals in blood [37], fur above the saphenous vein region was removed with a razor and depilation cream before the i.c.v infusion. At the desired time point after i.c.v. infusion, mice were anesthetized with ket/met as described above. Mice were then positioned under a Zeiss StereoLumar.V12 stereomicroscope with AxioVision software (Carl Zeiss, Feldbach, Switzerland) and a Photometrics Evolve 512 camera (Photometrics, Tucson, AZ) in a supine position on a heating pad $\left(37^{\circ} \mathrm{C}\right)$ for imaging. The autofluorescence signal on the GFP channel was used to position the saphenous blood vessels at $64 \times$ zoom. An image under the $\mathrm{Cy} 5$ filter was acquired with exposure time and camera gain settings of $200 \mathrm{~ms}$ and 200, respectively.

For dynamic imaging of tracer outflow to blood with different infusion rates, mice were positioned within $5 \mathrm{~min}$ after the completion of infusion under the stereomicroscope as above. Dynamic imaging was initiated 5 min after the completion of the ventricle infusion by acquisition of a sequence of images ( 1 image every $15 \mathrm{~s}$ for $55 \mathrm{~min}$ ) with a Cy 5 filter set to monitor the NIR signal of the saphenous vein. Exposure time and camera gain settings were $200 \mathrm{~ms}$ and 200, respectively.

\section{Assessment of lymphatic transport to blood}

Using AxioVision software, a circular region of interest (ROI) of radius $100 \mu \mathrm{m}$ was placed over the saphenous vein on the acquired images. The mean signal intensity was then recorded within this region. For quantification of signal enhancement, tissue background signals were subtracted using the mean values from three uninjected mice with the same image acquisition settings.

For the dynamic imaging, a table of fluorescence intensity in counts versus time was exported into Microsoft Excel using the measure profile function. Since there was a slight loss of signal at the beginning of the scans due to photo bleaching of tissue autofluorescence, baseline intensity in counts was calculated as an average signal of the lowest ten consecutive imaging frames. This baseline intensity was then subtracted from the fluorescence intensity values in order to plot fluorescent signal enhancement versus time in $\min$. The transport time to blood was determined as the point at which signal enhancement value was 100 counts above baseline levels.

\section{Analysis of tracer distribution on the brain surface and in CNS-draining lymph nodes}

Images of P40D680 tracer spread on the surfaces of the brain and within the deep cervical and mandibular lymph nodes were acquired with a Zeiss AxioZoom V16 microscope and a QImaging OptiMOS sCMOS camera (QImaging, Surrey, Canada) combined with a light-emitting diode illumination system pE-4000 (CoolLED Ltd, Andover, UK) and ZEN 2 software (Carl Zeiss, Feldbach, Switzerland). In excised brains, images were acquired over the contralateral dorsal hemisphere $(20 \times, 20 \mathrm{~ms}$ exposure) and of the entire ventral side of the brain $(11.2 \times, 200 \mathrm{~ms}$ exposure). Images of lymph nodes were acquired in situ at $25 \times$ and $200 \mathrm{~ms}$ exposure time. Since there were no apparent differences in signal in the lymph nodes on the injected and contralateral sides, the average value of the nodes from each side was used. For quantification of signal enhancement, tissue background signals were subtracted using the mean value from three uninjected mice with the same image acquisition settings.

\section{In vivo imaging through the skull}

After i.c.v. tracer infusion, the mouse was transferred to the microscope and the head fixed in a stereotactic frame on a heating pad $\left(37^{\circ} \mathrm{C}\right)$. The skull was kept hydrated with warmed PBS under a glass coverslip, and dynamic imaging of the contralateral half of the brain was carried out for a maximum of $60 \mathrm{~min}$ after tracer infusion through the skull of the anesthetized mouse using a Zeiss StereoLumar.V12 stereomicroscope (as described above). Dynamic imaging through the skull was carried out with a gain of 300 and an exposure time of $50 \mathrm{~ms}$ (Cy5 filter for P40D680 tracer) or $200 \mathrm{~ms}$ (ICG filter for P40D800 tracer). In some cases, imaging was continued during administration of an overdose of $400 \mathrm{mg} / \mathrm{kg}$ ketamine and $1 \mathrm{mg} / \mathrm{kg}$ medetomidine (i.p.), or after an overdose with ketamine/medetomidine followed by transcardiac perfusion with ice-cold PBS. 
For determination of CSF dynamics, circular ROIs of $1 \mathrm{~mm}$ diameter were placed over the location of the contralateral lateral ventricle and over the location of the quadrigeminal cistern in the acquired video using ImageJ/FIJI. Signal intensity within these ROIs was determined over time.

\section{Magnetic resonance imaging}

Animals were examined in a horizontal-bore 9.4 $\mathrm{T}$ animal scanner (BioSpec Avance III 94/20; Bruker Biospin GmbH, Ettlingen, Germany) with a BGA12S gradient system with ParaVision 6.0.1 (Bruker Biospin $\mathrm{GmbH}$ ) and a linearly polarized coil with an inner diameter of $40 \mathrm{~mm}$ (Bruker Biospin $\mathrm{GmbH}$ ). Imaging was performed with a threedimensional time of flight gradient recalled echo sequence (3D-TOF-GRE) originally adapted for imaging of peripheral lymph vessels [41] with recovery time of $12.0 \mathrm{~ms}$, echo time of $2.5 \mathrm{~ms}$, flip angle $25^{\circ}$, matrix $600 \times 400 \times 180$, field of view $36.00 \mathrm{~mm} \times 25.92 \mathrm{~mm} \times 18.00 \mathrm{~mm}$, zero fill 2 , 1 average and a scan time of 4 min 19 s 200 ms. Signal intensity (SI) reduction in blood vessels was achieved by placement of a saturation slice over the mouse heart.

Three-dimensional maximum intensity projection (MIP) reconstructions, SI and noise measurements were performed with ParaVision 6.0.1 (Bruker Biospin GmbH). For SI analysis, ROIs were created manually in a single slice per measurement, $1 \mathrm{~mm}$ dorsal to the circle of Willis. For SI measurements in cortical parenchyma and noise determination from background SI, identically sized circular ROIs were employed, while cortical tissue containing vessels was segmented manually (see Supplemental Fig. 4).

For animals in which injection of MRI contrast medium was not successful (wrong location of the injection or significant backflow from the injection site), MR imaging experiments were discontinued.

\section{Brain sections}

Mouse brains were dissected and fixed in $4 \%$ PFA at $4{ }^{\circ} \mathrm{C}$ for $48 \mathrm{~h}$. A section of the brain between $1 \mathrm{~mm}$ rostral and $1 \mathrm{~mm}$ caudal to the needle insertion site was cut out by razor blade. Coronal sections were made from dorsal to ventral side at a thickness of $100 \mu \mathrm{m}$ with a vibratome (Leica VT1000 S). Images were acquired with a Zeiss AxioZoom V16 microscope and ZEN 2 software.

\section{Analysis of tracer influx into the brain parenchyma}

The percentage area of tracer coverage in brain sections was determined using ImageJ/FIJI as follows. The cerebral cortex was selected as an ROI on images of coronal brain sections. A uniform threshold was applied to all images, and background signal manually erased. The percentage area coverage of the signal within the ROI was determined. Analysis of all images was independently carried out in a blinded manner by two investigators, and an average was taken of six coronal sections per mouse.

The deepest tracer penetration within the dorsal cerebral cortex was determined using lines drawn perpendicular to the brain surface with ImageJ/FIJI. The two largest values were taken for the injected and contralateral sides, and an average of these four values was taken for six sections per mouse by two independent investigators. Due to clear differences between images from perfused and non-perfused brains, blinding was not feasible for this analysis.

\section{Statistics}

Mice were randomly allocated to different experimental groups. Group sizes were estimated based on pilot studies to determine the success rate and reproducibility of the intraventricular infusions. All data are presented as mean \pm SD. Means of two groups were compared using an unpaired twotailed Student's $t$ test. Means of three groups were compared with one-way ANOVA with the Tukey's multiple comparison post hoc test. Correlation analysis was done using Pearson's correlation. All analyses were performed using GraphPad Prism V5.0 (GraphPad Software, San Diego, CA) and $p<0.05$ was accepted as statistically significant.

\section{Results}

\section{Outflow of CSF increases during awake conditions}

Using dynamic near-infrared fluorescence imaging, we have previously demonstrated that CSF-infused tracers reach the systemic circulation in anesthetized mice by transport through the lymphatic system rather than via a direct outflow from the subarachnoid space to venous blood [37]. With this in mind, we first aimed to determine the levels of CSF-injected tracer that reached the systemic blood in mice that were allowed to wake after i.c.v. infusion versus mice that were maintained under anesthesia. As shown in the experimental design scheme in Fig. 1a, three groups of mice were assessed for CSF transport to blood at $60 \mathrm{~min}$ after lateral ventricle infusion of a $40 \mathrm{kDa}$ bulk flow tracer [37]. Two groups of mice were infused with $2.5 \mu \mathrm{L}$ of $200 \mu \mathrm{M}$ P40D680 over the course of 2.5 min under isoflurane anesthesia. After suture of the skin above the skull, mice in the awake group were allowed to recover and move normally within the cage, while mice in the isoflurane group were maintained on a heating pad under isoflurane. At $60 \mathrm{~min}$ after the i.c.v. infusion, both groups of mice were injected with ketamine/medetomidine (ket/med) for in vivo imaging of tracer signal within the saphenous vein. A third 
a

\begin{tabular}{|c|c|c|c|c|c|}
\hline Awake & $\begin{array}{c}\text { Tracer infusion } \\
\text { under } 2 \% \text { isoflurane }\end{array}$ & Awake \\
Isoflurane & $\begin{array}{c}\text { Tracer infusion } \\
\text { under } 2 \% \text { isoflurane }\end{array}$ & Anesthetized under isoflurane \\
\hline Ket/med & $\begin{array}{c}\text { Tracer infusion } \\
\text { under Ket/med }\end{array}$ & Anesthetized under Ket/med \\
\hline
\end{tabular}

Suture
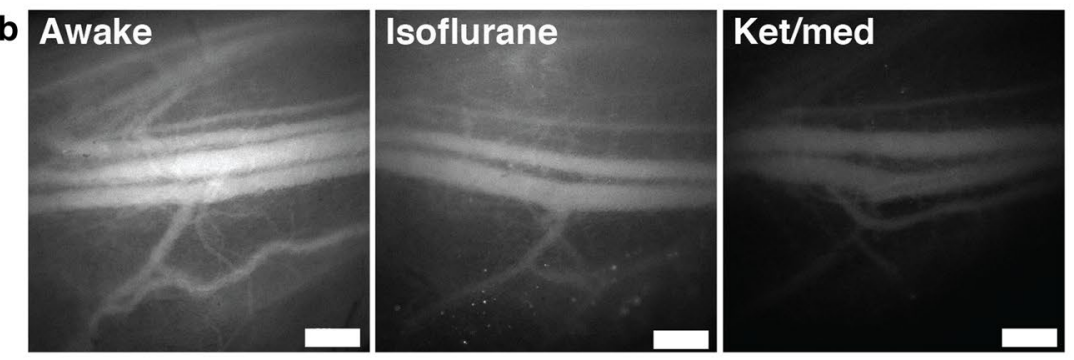

d
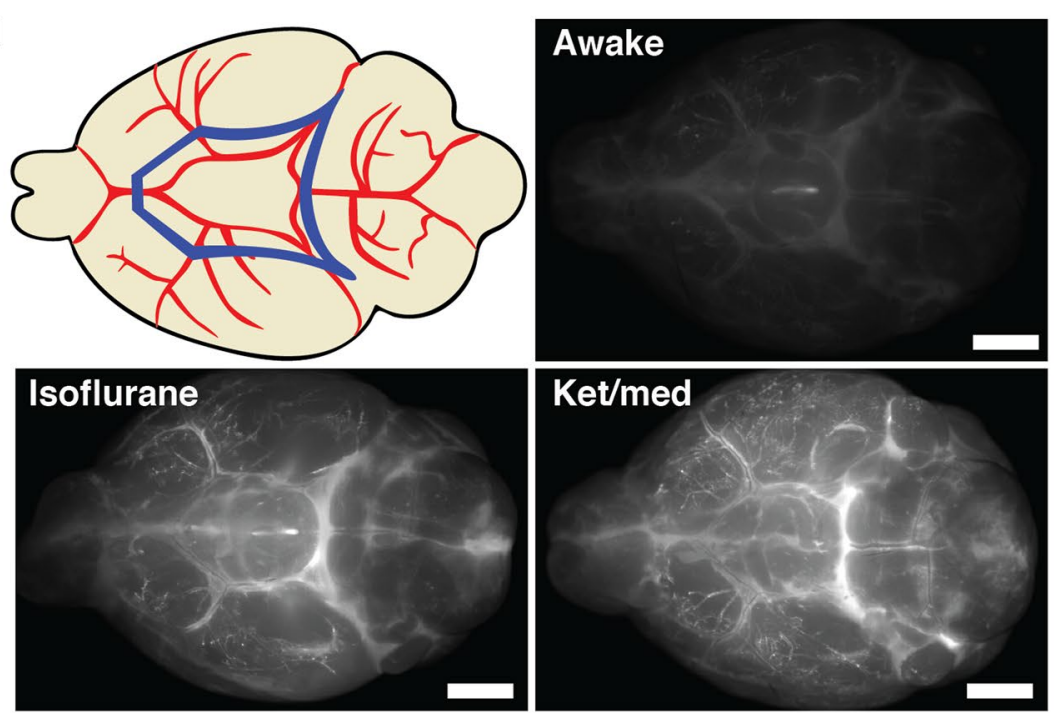

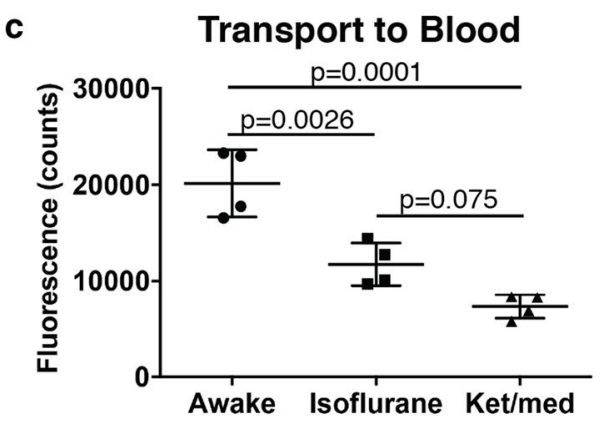

e

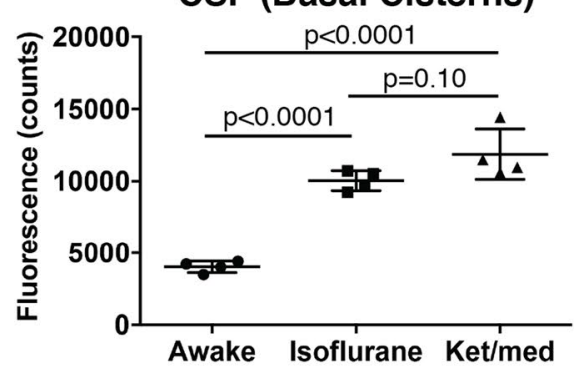

Fig. 1 CSF outflow is increased during awake conditions. a Scheme of experimental design for quantification of CSF outflow during awake or anesthesia conditions. Before imaging at the saphenous vein, mice from awake and isoflurane group were given $80 \mathrm{mg} / \mathrm{kg}$ ketamine, $0.2 \mathrm{mg} / \mathrm{kg}$ medetomidine intraperitoneally. After imaging, all mice were overdosed with $400 \mathrm{mg} / \mathrm{kg}$ ketamine, $1 \mathrm{mg} / \mathrm{kg}$ medetomidine. b Representative images of saphenous bundle of blood vessels at 60 min post-infusion of P40D680 into lateral ventricle. Scale bar:
$500 \mu \mathrm{m}$. c Quantification of P40D680 signal in the blood 60 min after tracer i.c.v. infusion. $\mathbf{d}$ Scheme indicating ROI and ex vivo imaging of the basal aspect of the brain at $60 \mathrm{~min}$ post-infusion showing presence of P40D680 tracer at circle of Willis and cisterns. Blue polygon in upper left image represents the analyzed ROI. Scale bar: $2000 \mu \mathrm{m}$. e Quantification of P40D680 signal at basal cisterns $60 \mathrm{~min}$ after infusion group (ket/med group) was kept under ket/med anesthesia for the duration of the infusion, maintenance and imaging procedures.

Using a fluorescence stereomicroscope, imaging of P40D680 signal within the saphenous vein indicated that mice from the awake group had significantly increased tracer levels within the systemic blood at 60 min compared to mice that were maintained under either anesthetized condition (Fig. 1b-c). The tracer levels at $60 \mathrm{~min}$ in awake mice corresponded to $62.9 \pm 10.9 \%$ of the i.c.v infused tracer present 
within the blood when compared to the fluorescent signals in mice that were intravenously injected with the same dose $(20,149 \pm 3490$ vs. $32,018 \pm 718$ counts $)$. After killing the mice via ket/med overdose and harvesting the brains, we compared the signals of P40D680 that remained at the basal cisterns around the circle of Willis as another measure of CSF clearance (Fig. 1d). As expected, mice in the awake group had significantly less P40D680 remaining at $60 \mathrm{~min}$ compared to mice that were under either type of anesthesia (Fig. 1e). These results indicate that clearance of CSFinfused tracers is increased during awake conditions, consistent with our findings of enhanced lymphatic clearance during awake conditions in other regions of the body [44].

\section{Dynamics of CSF outflow support lymphatic efflux}

Since a significant portion of the injected dose quickly reaches the systemic blood in the awake mice, we aimed to provide support that CSF outflow occurs through lymphatic vessels under these conditions. As live monitoring of the dynamics of tracer transport to systemic blood in awake mice is not feasible, we killed mice at four different time points $(15,30,60$ and $90 \mathrm{~min})$ after i.c.v. infusion to assess tracer levels in the blood, the basal cisterns and the CNSdraining lymph nodes. We compared the signals in mice that were allowed to wake to signals from mice that had been infused and maintained under ket/med (Fig. 2a), conditions where we have previously demonstrated that CSF tracer outflow occurs predominantly through a lymphatic route [37].

At 15 min after i.c.v. infusion, tracers were already present at low levels in systemic blood in the awake group, but the signals were not above background levels in the ket/med group (Fig. 2b). The signals in blood increased over time in both groups and were 5.7-fold higher at $30 \mathrm{~min}, 3.0$-fold higher at $60 \mathrm{~min}$ and 1.8-fold higher at $90 \mathrm{~min}$ in awake mice compared to ket/med mice. The signal intensity at the basal cisterns showed an opposite pattern with significantly lower levels of tracer remaining at 30,60 and 90 min in the awake group (Fig. 2c). Intensity of the signals in the CNSdraining deep cervical and mandibular lymph nodes imaged in situ at 15 min showed higher levels in the awake group; however, no significant differences between the two groups were apparent at $30 \mathrm{~min}$ (Fig. 2d-f). At 60 and $90 \mathrm{~min}$, the levels of tracer in both deep cervical and mandibular lymph nodes in awake mice were significantly lower than those in ket/med mice, consistent with the observation that most of the infused tracer in the awake mice had already reached the systemic blood.

As further evidence for lymphatic clearance of CSF under awake conditions, we next aimed to demonstrate a time point shortly after recovery from anesthesia at which signals could be found within the lymphatic system but not yet in the systemic blood. This was challenging as blood signals were already elevated at the $15 \mathrm{~min}$ time point in the awake group, as shown in Fig. 2b. We speculated that a reduced infusion rate and volume may slow down the dynamics of CSF outflow, which has been shown to be dependent on intracranial pressure $[9,23,39]$. To test this, we infused into the lateral ventricle identical doses of P40D680 but at different volumes and rates. This led to clear effects on the transport to blood with a delay in the transport time when the lowest volume was infused (Supplementary Fig. 1a, b). Therefore, we infused $1 \mu \mathrm{L}$ of $500 \mu \mathrm{M}$ P40D680 and killed the mice at $10 \mathrm{~min}$ after i.c.v. infusion, shortly after the mice had awakened (Supplementary Fig. 1c). As shown in the representative mouse in Supplementary Fig. 1d, using this protocol we could not detect tracer within the bloodstream (above the assay sensitivity of $0.2 \%$ of the infused dose [37]), but found that tracer was readily detected in the collecting lymphatic vessels and draining lymph nodes by $10 \mathrm{~min}$ after tracer infusion (Supplementary Fig. 1e). In sum, these dynamic imaging results support the conclusion that CSF clearance occurs rapidly through lymphatic vessels in mice during awake conditions.

\section{Distribution of tracers to the PVS is inversely correlated with CSF outflow}

Glymphatic (paravascular) influx of CSF-injected tracers into the brain has been found to be reduced in awake mice compared to those under sleeping or anesthetized conditions [54]. Therefore, we next assessed whether the rapid tracer efflux from the CSF that we observed during awake conditions could affect the spread of the tracers to the PVS of the brain surface and the parenchyma of the brain. Similar to the levels of tracer intensity demonstrated in the basal cisterns (Fig. 1d), there were obvious differences in the amount of tracer located within PVS on the dorsal brain surface and parenchyma of the brain (Fig. 3a, b). Mice anesthetized with ket/med demonstrated an increased signal intensity on the surface of the brain, with a clear PVS pattern observed, compared to mice that were awake (Fig. 3c). Mice under isoflurane anesthesia showed an intermediate pattern of tracer spread. The PVS within the brain parenchyma also presented with significantly increased tracer signal in the $\mathrm{ket} / \mathrm{med}$ group compared to mice in the isoflurane and awake groups (Fig. 3d).

We then pooled the data from mice analyzed under all three conditions at the 60 min time point and performed correlation analyses to determine whether there were any significant relationships between the tracer levels within the blood, at the basal cisterns and within the PVS of the brain surface. These analyses showed clearly that the spread of tracer to the PVS of the brain surface was directly related to the amount of tracer remaining at the basal cisterns and 
a

Awake

Tracer infusion under $2 \%$ isoflurane

Awake

Imaging

\begin{tabular}{|c|c|c|}
\hline \multirow[t]{2}{*}{ Ket/med } & $\begin{array}{l}\text { Tracer infusion } \\
\text { under Ket/med }\end{array}$ & Anesthetized \\
\hline & & $15,30,60$ or $90 \mathrm{~min}$ \\
\hline
\end{tabular}

Suture

b

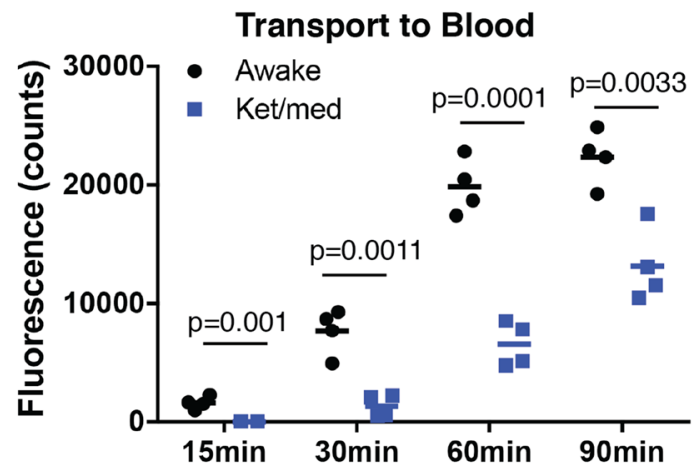

d
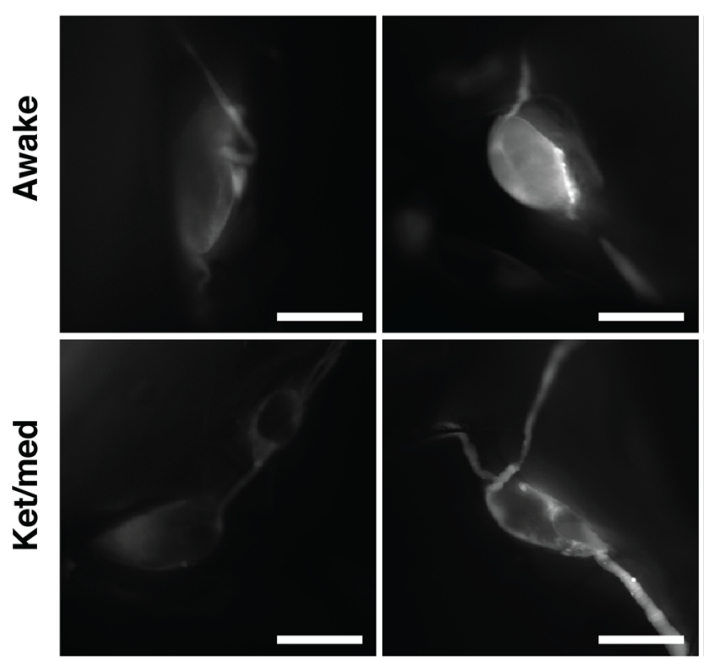

e

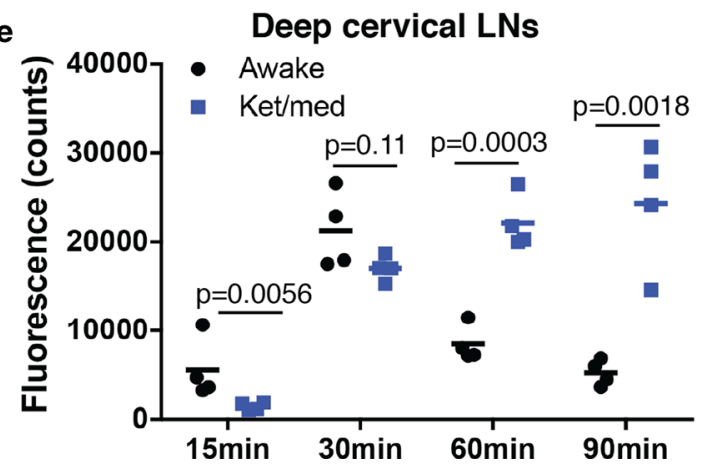

Fig. 2 Dynamics of outflow support CSF drainage through lymphatic vessels. a Scheme of experimental design for quantification of the dynamics of CSF outflow during awake or ket/med anesthesia conditions. b Quantification of P40D680 signals in the blood. c Quantification of P40D680 signals at basal cisterns. d Representative in situ

\section{c CSF (Basal Cisterns)}

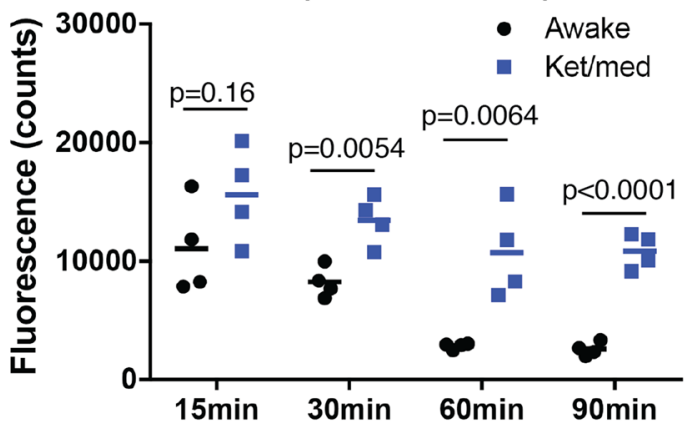

$60 \mathrm{~min}$

$90 \mathrm{~min}$
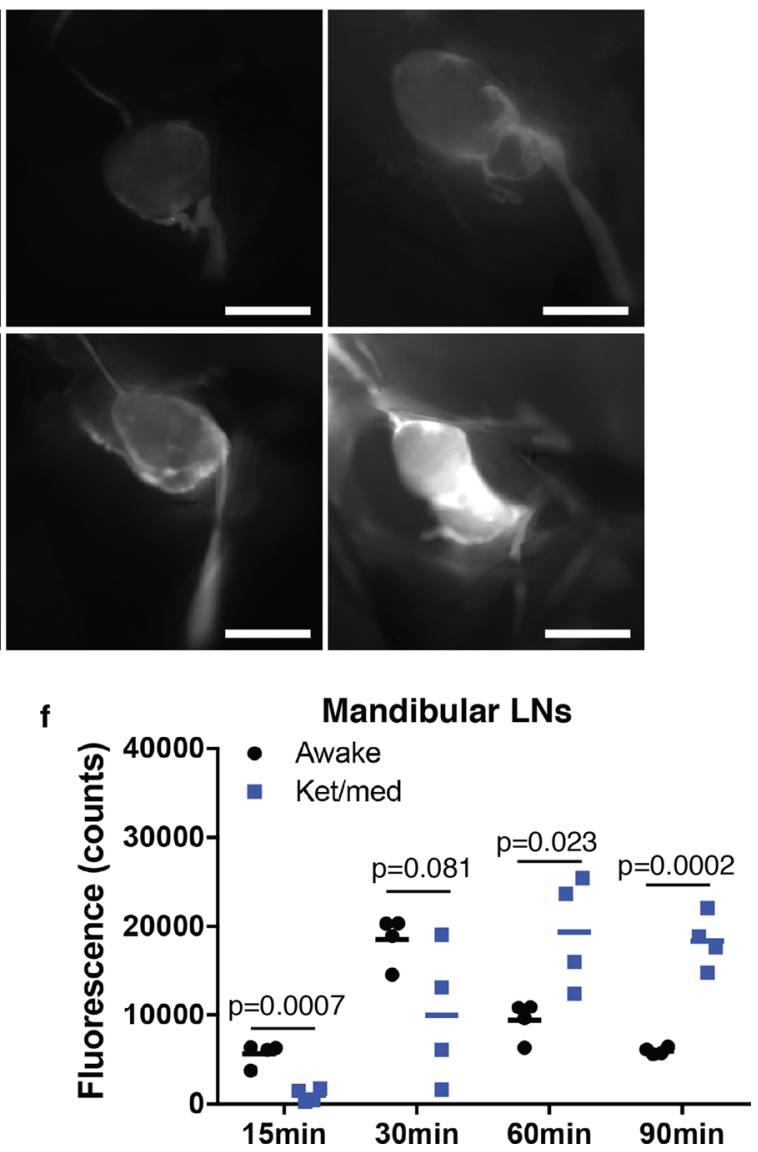

images of deep cervical LNs at 15, 30, 60 and 90 min post-infusion of P40D680 into lateral ventricle. Scale bars: $1000 \mu \mathrm{m}$. e Quantification of P40D680 signals in the deep cervical lymph nodes (LNs). $\mathbf{f}$ Quantification of P40D680 signals in the mandibular LNs 

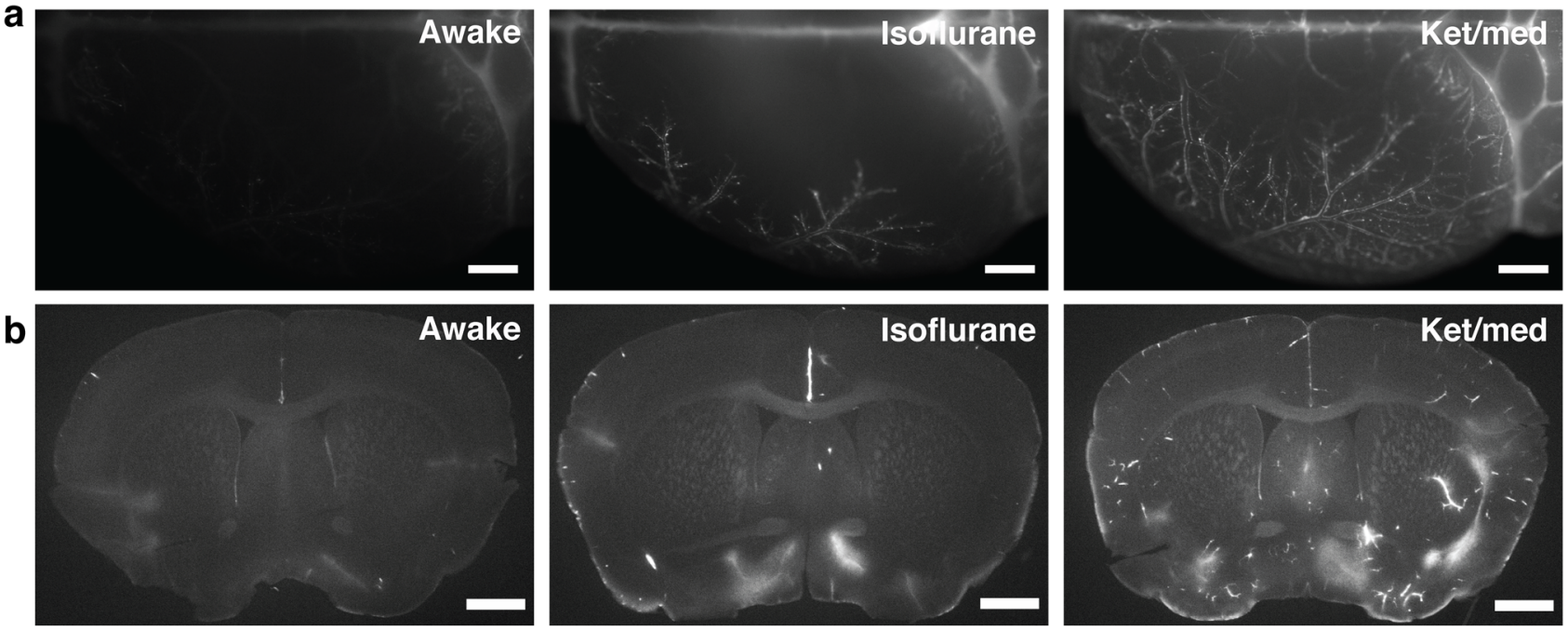

C

PVS brain surface

d

PVS cortex

$\mathrm{p}=0.0031$
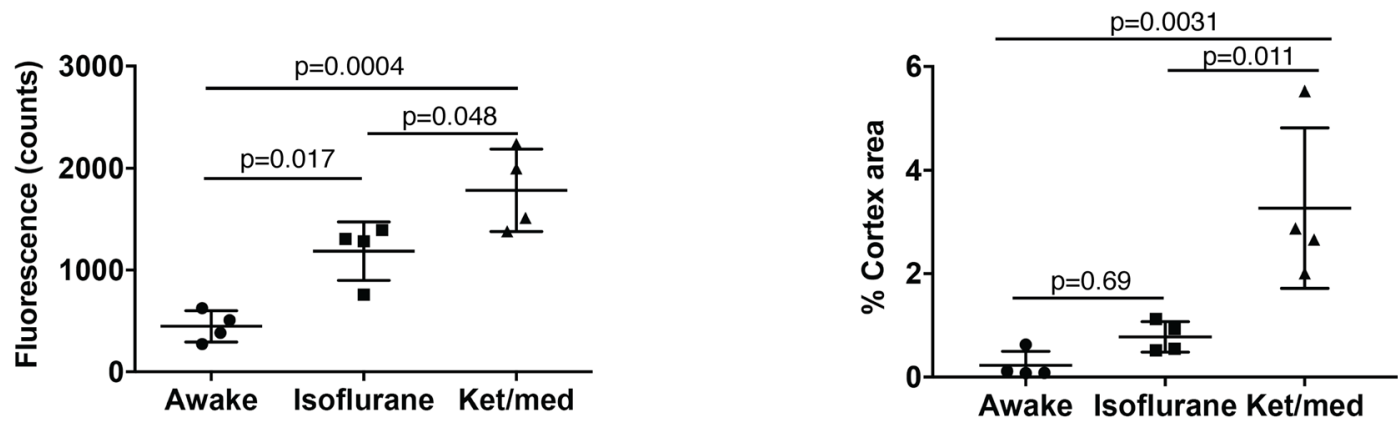

e
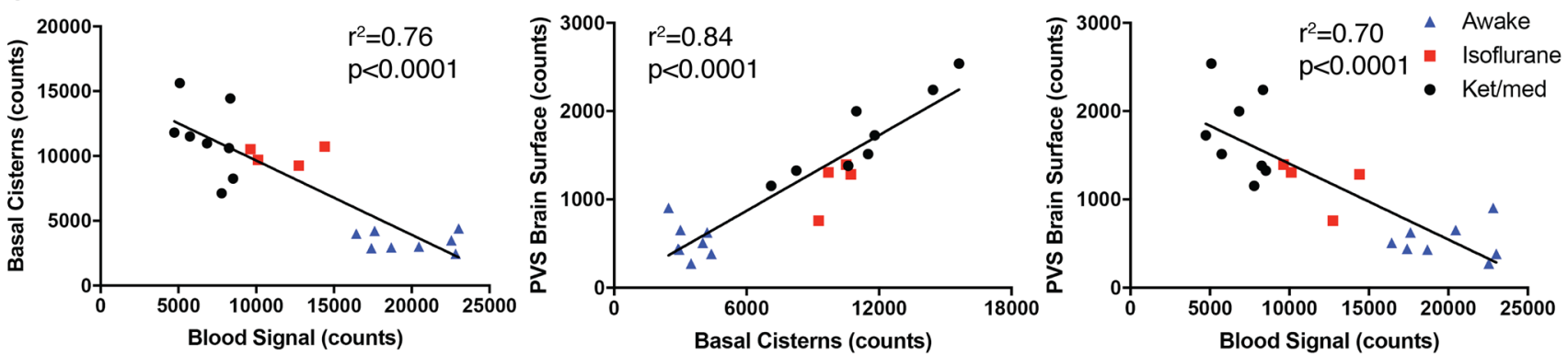

Fig. 3 Spread to paravascular space (PVS) is inversely correlated to CSF outflow. a Representative images of tracer-filled PVS on the brain surface of the dorsal hemisphere contralateral to the infusion site. Scale bars: $1000 \mu \mathrm{m}$. b Representative images of tracer accumulation in PVS around penetrating vessels on $100 \mu \mathrm{m}$ brain sections. Scale bars: $1000 \mu \mathrm{m}$. c Quantification of P40D680 signal on the brain

indirectly proportional to the amount that had reached the systemic blood (Fig. 3e). These findings support the concept in which rapid outflow of CSF-administered tracers observed during awake conditions limits the distribution of tracers to the PVS (Supplementary Movie 1).

surface 60 min after infusion. d Quantification of P40D680 signal in the cortex of the $100 \mu \mathrm{m}$ brain sections $60 \mathrm{~min}$ after infusion. e Correlations from all mice examined at 60 min demonstrating relationships between signals at basal cisterns, brain surface and systemic blood. All quantifications are normalized to signals in $n=3$ uninjected mice

\section{Tracers accumulated within PVS of the brain surface around both arteries and veins, even at early time points}

Close examination of the surface of the brain at 60 min indicated that tracers were found not only along brain surface arteries, but also along veins (Supplementary Fig. 2a). We confirmed this using a SMMHC-GFP reporter mouse where 
contractile arterial smooth muscle cells (SMC) show green fluorescence. The tracer was localized outside the SMC layers of the arteries (Supplementary Fig. 2b), consistent with a "paravascular" rather than a "perivascular" or "intramural" location as defined by Engelhardt et al. [18]. Surprisingly, even in mice that were killed only 2 min after the completion of the infusion into the ventricles, we were able to detect the presence of tracer along branches of the caudal rhinal veins (Supplementary Fig. 2c). In these mice, there was no obvious tracer penetration into the parenchyma; therefore, the tracer spread from PVS of arteries to veins did not appear to be occurring within the brain (Supplementary Fig. 2d). These results indicate that pathways for CSF flow may exist between the PVS of arteries and veins at the brain surface.

a
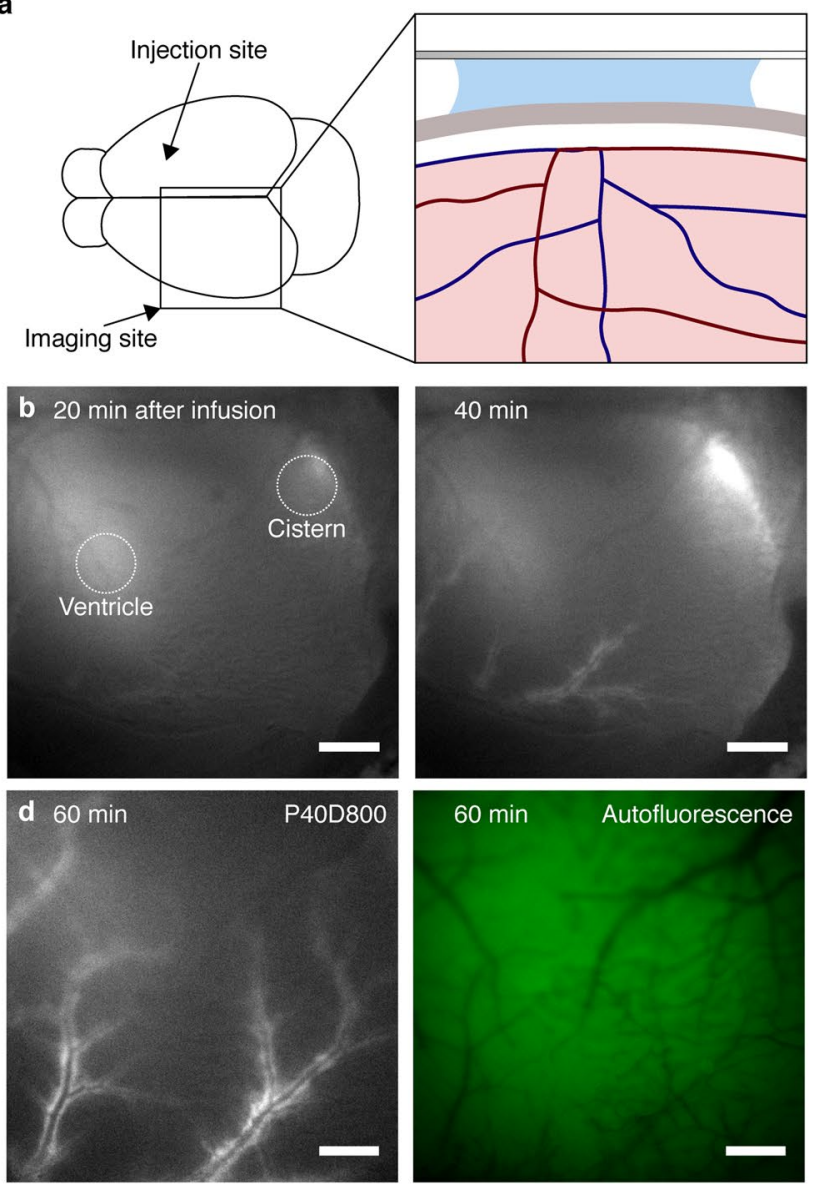

Fig. 4 Tracer spread from the CSF is limited to PVS of surface blood vessels in vivo. a Schematic illustration of setup for in vivo nearinfrared imaging through the skull. b Representative images of tracer spread along brain surface blood vessels visualized through the skull 20,40 and 60 min after infusion of $2.5 \mu \mathrm{L} 200 \mu \mathrm{M}$ P40D800 into the contralateral ventricle. Scale bars: $1000 \mu \mathrm{m}$. Dotted circles show $1 \mathrm{~mm}$ diameter ROIs used for quantification of tracer signal from lat-

\section{Through-skull in vivo imaging demonstrates spread of tracers within the PVS of large-caliber vessels of the brain surface}

We hypothesized that the spread of tracers within the PVS of the brain surface in mice anesthetized with ket/med might be demonstrated in vivo using NIR imaging through the intact skull. To establish this assay, we infused P40D800 tracer into the right lateral ventricle and imaged over the left cortical hemisphere through the skull of the mouse with a NIR-sensitive fluorescence stereomicroscope (Fig. 4a). The longer wavelength P40D800 tracer exhibits similar properties to the P40D680 tracer but allows NIR imaging with better depth penetration and lower tissue autofluorescence. When imaging was initiated at $20 \mathrm{~min}$ post i.c.v. infusion, tracer signals emanating from the lateral ventricles and cisternal spaces of CSF, such as the quadrigeminal cistern, were seen (Fig. 4b).

\section{Cover slip \\ PBS \\ Skull \\ CSF \\ Brain \\ Vein \\ Artery}

(m)
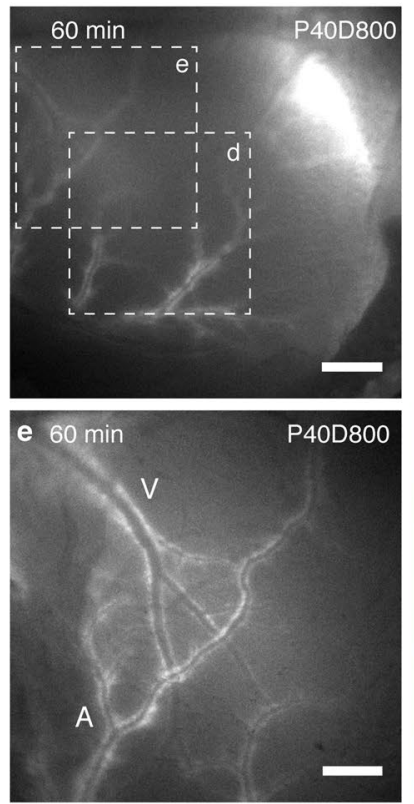

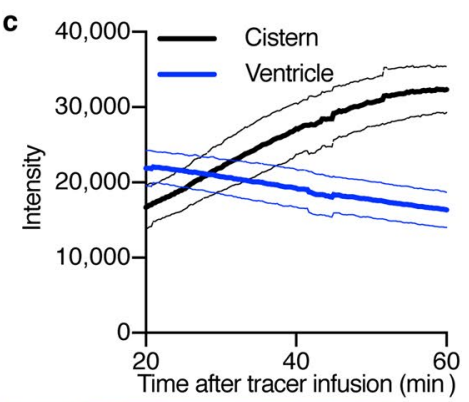

$60 \mathrm{~min}$

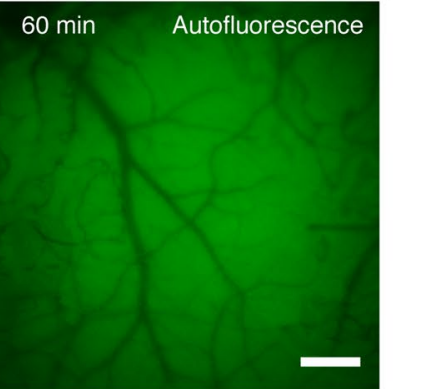

eral ventricle and quadrigeminal cistern. c Quantification of fluorescence signal from the lateral ventricle (blue) and quadrigeminal cistern (black) after tracer infusion as in $(\mathbf{b})(n=5)$. Data show mean (solid lines) \pm SD (dashed lines). d-e Close-ups of region shown in (b) with corresponding autofluorescence images $60 \mathrm{~min}$ after tracer infusion indicating tracer spread along large surface arteries (A) and transfer to surface veins (V). Scale bars: $500 \mu \mathrm{m}$ 
Quantification of videos of these regions over time showed an expected loss of signal from the ventricles concurrent with an increasing signal from the CSF in the quadrigeminal cistern (Supplementary Movie 2, Fig. 4c). During this time, tracer signals became apparent along the middle cerebral artery (MCA) and its branches and slowly spread within the network of PVS around these vessels (Fig. 4b, d). In some mice, we could observe a spread of tracer from the PVS of the branches of the MCA to some of the larger veins such as the dorsal middle cerebral and dorsal rostral cerebral veins (Supplementary Movie 3, Fig. 4e). However, at no point in time was it obvious that there was a spread of tracer from the larger brain surface arteries to the penetrating arteries entering the cortex. Therefore, we conclude that under our in vivo experimental conditions, the spread of tracer over the dorsal hemisphere is confined to the large caliber arteries and veins at the brain surface.
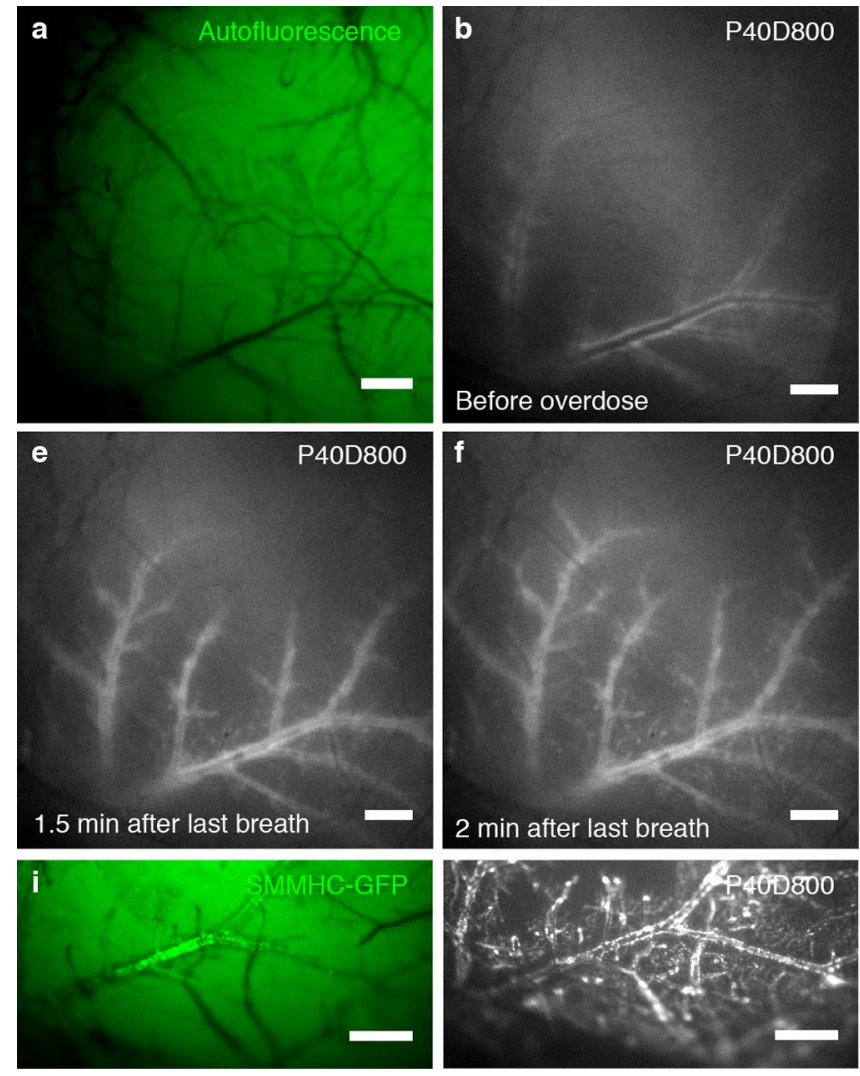

Fig. 5 Extensive post-mortem tracer spread on brain surface and to penetrating blood vessels. a-h Images of tracer spread visualized after infusion of $2.5 \mu \mathrm{L} 200 \mu \mathrm{M}$ P40D800 into the contralateral ventricle. Imaging through the skull (a-g) or after skull removal (h). a Autofluorescence image of brain region imaged. b Tracer spread 60 min after infusion of $2.5 \mu \mathrm{L} 200 \mu \mathrm{M}$ P40D800 into the contralateral ventricle. c Tracer spread after overdose with ket/med i.p. but before last breath. d Tracer spread $1 \mathrm{~min}$ after last breath. e Tracer spread 1.5 min after last breath suggesting constriction of arteries initiating from the MCA. $\mathbf{f}$ Tracer spread 2 min after last breath showing

\section{Rapid paravascular spread of tracers into the brain parenchyma after death}

Our imaging experiments revealed discrepancies between in vivo and ex vivo patterns of tracer within the PVS. In vivo, the tracer-filled spaces appeared wider [5], there was a more limited spread to the PVS over the dorsal hemispheres and there was no obvious penetration of tracers along cortical blood vessels despite being clearly evident on brain sections (Fig. 3b). Therefore, we speculated that a post-mortem artifact might be present that could explain these differences.

To test this, we acquired videos through the skull of mice before and during an overdose with ket/med. Mice were imaged in vivo until $60 \mathrm{~min}$ after tracer infusion, at which point the tracer spread was limited to the larger surface vessels, especially the MCA (Fig. 5a, b, Supplementary Movie
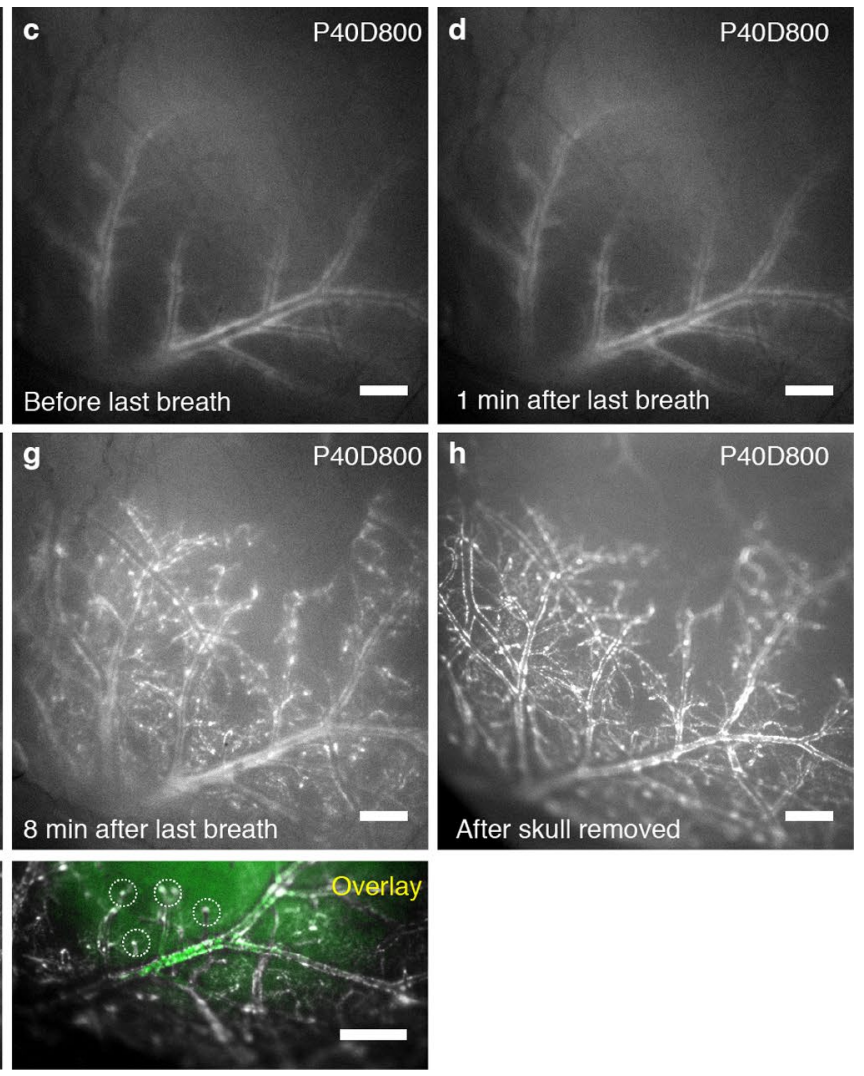

spreading of arterial constriction to smaller branches of the MCA. $\mathbf{g}$ Tracer spread $8 \mathrm{~min}$ after last breath showing spreading to penetrating blood vessels. h Imaging of tracer spread after skull removal indicating that signal detection was not significantly obstructed by imaging through the skull. i Images of tracer spread in brain of SMMHC-GFP mouse ex vivo $60 \mathrm{~min}$ after infusion of $2.5 \mu \mathrm{L} 200 \mu \mathrm{M}$ P40D800 into the lateral ventricle. SMMHC-GFP positive vessels (green) mark arteries with contractile smooth muscle cells. Circles indicate location of tracer (white) at penetrating blood vessels. Scale bars: $500 \mu \mathrm{m}$ 
4). We then overdosed the animal via i.p. injection of a lethal dose of ket/med. During the next few minutes, there was a minimal further spread of tracer while the animal exhibited gasping activity (Fig. 5c). Immediately after the final breath was taken, a wave was seen to spread through the cortex that originated laterally with vasoconstriction of the large branches of the MCA and spread medio-dorsally over the surface of the cortical hemisphere (Supplementary Movie 4). Following this wave, there was an advance of tracer towards the smaller branches of the MCA and the penetrating arteries, as well as to the venous PVS (Fig. 5d-g). Comparison of the images from the same mice before and after skull removal clearly demonstrated that the images acquired through the skull revealed the true extent of tracer spread (Fig. 5h). Notably, tracer signal at the penetrating vessels was only apparent after death (Fig. 5i).

We next confirmed that an influx to the PVS was occurring after death using MRI. Infusions of a macromolecular contrast agent, Gadospin D, were performed into either the cisterna magna or the right lateral ventricle and a series of three-dimensional MRI datasets was then acquired with a T1-weighted sequence. After a period of approximately 40 min, one group of mice $(n=5)$ was overdosed with ket/ med while a control group $(n=5)$ was maintained under
Fig. 6 Spread of contrast agent to PVS after death as detected with MRI. a Visualization of tracer spread after infusion of $5 \mu \mathrm{L}$ of a Gadospin D solution at $25 \mathrm{mM}$ gadolinium into the cisterna magna; data acquired with a series of T1-weighted MRI measurements (threedimensional time of flight gradient recalled echo sequence). MIP images on the upper panel show a mouse that was kept alive under ket/med anesthesia and showed no spread of the tracer towards the PVS. The bottom panel images show a mouse that was overdosed with ket/med; the time of death is indicated as $t=0$. Strong enhancements of signal are detectable 9 min after death at the circle of Willis (CoW) and at the middle cerebral artery (MCA). Smaller branches of the MCA are clearly visible $27 \mathrm{~min}$ after death. b, c Quantification of signal-to-noise ratio (SNR) after tracer infusion in the cisterna magna in mice kept under $\mathrm{ket} / \mathrm{med}$ anesthesia $(n=5)$ or in mice killed by ket/med overdose $(n=5)$. Regions of interests were defined on the surface of the cortex (b) and the cortical parenchyma (c). SNR values were normalized to the time of death and set to time $=0$. Data show mean \pm SD. d Comparison of the slopes calculated by linear regression of SNR over time for the surface of the cortex and for cortical parenchyma in the control group and in the group of mice killed by ket/med overdose a
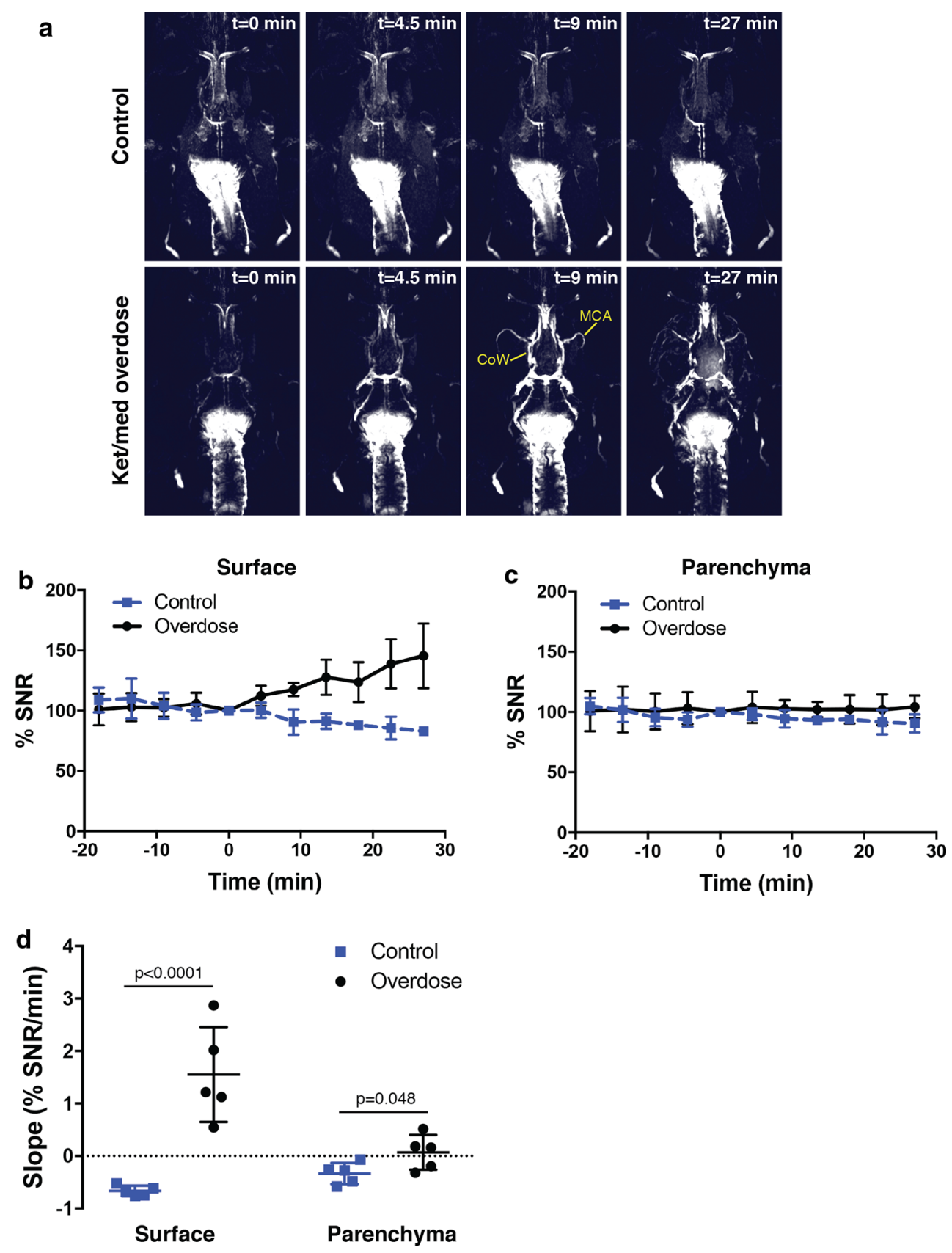
ket/med anesthesia. Clear enhancements of signal occurred at the circle of Willis and the MCA after death that was not apparent in the control groups (Fig. 6a, Supplementary Fig. 3, Supplementary Movies 5 and 6). Next, we performed quantification in mice that were infused through the cisterna magna since they did not have interfering signals from the ventricles. Signal-to-noise ratio measurements were made using ROIs on the surface of the cortex (assumed to be PVS) and the cortical parenchyma (Supplementary Fig. 4). After normalization of the signals to the time of death (set to time $=0$ ), these assessments revealed that the slope of the signal increase was significantly greater in both regions after death when compared to the control mice (Fig. 6b-d). Importantly, no detectable influx of contrast agent occurred in the parenchyma of the in vivo control group at any point after infusion.

We also tested whether cardioperfusion would limit the spread of tracers to the parenchyma at the time of death. Videos acquired immediately after the completion of perfusion demonstrated that the spread of tracers was also occurring post-mortem under these conditions (Supplementary Movie 7). Assessment of the influx depth of tracer spread in the PVS of the parenchyma demonstrated no difference between mice killed by overdose or via cardioperfusion (Supplementary Fig. 5). We conclude that shortly after death a significant spread of tracer occurs through the PVS of the larger surface vessels to the PVS of the parenchyma.

\section{Discussion}

In this study, we demonstrated using intraventricular infusions of a bulk flow tracer and fluorescence stereomicroscopy that CSF outflow was increased in awake mice compared to anesthetized mice. Evaluation of the dynamics of this outflow supports the conclusion that CSF clearance occurs through the lymphatic system in this species. An inverse relationship was found between the efflux of CSF to the systemic blood and the spread of CSF tracers to the paravascular spaces as assessed ex vivo. In vivo imaging of PVS spread of tracers at the brain surface demonstrated that this spread was limited to the PVS of larger caliber arteries and veins. Finally, we found that a rapid influx of tracers to the PVS of the cortical parenchyma occurred just after the death of the animal.

A substantial increase in the outflow of CSF tracers to the systemic blood in awake mice was found compared to mice that were anesthetized. There is very little similar data to compare to regarding this point, although one previous report demonstrated increased CSF clearance of radiolabeled tracer from the spine in active compared to resting subjects [17]. It is likely that physical activity affects CSF pressure and increases flow towards efflux pathways. Respiration and arterial pulse are driving forces for CSF flow and mixing $[16,20]$ and the rates of both are naturally higher in awake versus anesthetized animals. These results also lend further support for a CSF outflow pathway that is predominantly lymphatic in nature $[9,37]$. Lymphatic clearance is highly dependent on muscular activity and transport through lymphatic vessels is dramatically increased when the subject is awake [22, 44, 49]. The concept of lymphatic rather than venous outflow of CSF still remains to be rigorously evaluated in humans, however, some evidence does exist to support this pathway in non-human primates and cadavers [31, 38].

An increased CSF outflow while awake is not fully consistent with the concept of increased CSF flushing through the brain during sleep or deeply anesthetized conditions [54]. In the glymphatic model, CSF within the arterial PVS serves as an input fluid to the brain. If the CSF turnover is rapid during awake conditions, this would limit access of CSF-infused tracers to the PVS, a factor that was not considered during the original study [25, 54]. Another recent MRI study has challenged the concept that increased glymphatic flow occurs in anesthetized mice compared to awake mice [21]. However, this study concluded that CSF influx was actually increased during awake conditions, which we have not found to be the case. It is unclear whether the tracer that was measured in the brain by MRI in vivo was intravascular after effluxing the CSF to reach the systemic circulation rather than a direct influx into the parenchyma from CSF as proposed by the authors. In addition, the low-molecular weight tracer used in this study as well as other recent MRI studies [7, 34, 47] would exhibit significant concentration gradient-dependent diffusion into the brain parenchyma and thus would not accurately demonstrate the bulk flow pathways of CSF.

It is important to note that it was not our aim to assess sleeping, unanesthetized mice with our methods, nor have we monitored clearance of tracer injected into the parenchyma. Therefore, theoretically, an increased clearance of metabolites from the brain might indeed occur under sleeping conditions. The destination for the efflux fluid in the glymphatic model is not exactly clear; one version of the model shows fluid exiting through the PVS around veins to reach the CSF while another proposes that there may be connections to lymphatic vessels within the dura mater [4, $28,35,36]$. However, we were unable to demonstrate any paravascular influx of CSF into the brain during anesthetized in vivo conditions and we have found significantly increased clearance of CSF under waking conditions. Therefore, at this point, it is difficult to imagine how an increased brain flushing during sleep via a bulk CSF influx through the glymphatic system could be occurring as originally envisaged.

The close correlation between signals in the basal cisterns and the PVS of the brain surface highlights the circle of 
Willis as an important potential access point for CSF and its components into the PVS. The circle of Willis is the main source of the arteries that feed into the brain. A recent study in rats has confirmed an earlier observation that stomata exist in the pia mater covering these arteries which may provide anatomical pathways for CSF and macromolecules from the basal cisterns to the PVS $[42,56]$. The major CSF outflow routes along several cranial nerves [37] (e.g., olfactory, optic, trigeminal) are located immediately rostral to the circle of Willis, indicating that CSF flow could be directed either out of the skull or into the arterial PVS depending on the physiological conditions.

Our data support the concept that some portion of CSF can spread to the brain surface PVS in vivo, at least under anesthetized conditions where there is reduced CSF outflow. We have also observed a spread of tracer from the PVS of arteries to the PVS of veins on the brain surface, consistent with the recently published concept of low resistance pathways for CSF flow at this location [6]. It will be interesting to examine at an anatomical level whether connections are present between the leptomeningeal sheaths of the PVS of arteries and veins. CSF may also spread along the large vessels that penetrate from the ventral aspect into the brain, such as into the midbrain as shown in MRI studies [15]. A recent MRI study in humans has shown that the diffusion of a low molecular weight contrast agent into the brain parenchyma correlated with the availability of the contrast agent in the surrounding CSF [47]. Thus, a dynamic balance between CSF turnover and CSF solute distribution to the brain may exist that could be altered under different physiological or pathological conditions.

The most surprising finding of this study was a major influx of tracer into the PVS that occurred immediately after the death of the animal. This observation was predicted by the prominent neuroscientist Lewis Weed who wrote in 1914 that "ordinarily, after death, cerebrospinal fluid is aspirated by the brain" [53]. One might expect that the substantial loss of blood pressure that occurs within the brain at death would establish a gradient for flow from the CSF to the brain parenchyma [53]. Thus, quantifications of tracer that are performed within the PVS or parenchyma of the brain ex vivo are likely overestimates of the levels that are present in vivo. This phenomenon may also account for some of the previous findings based on ex vivo assessments that have concluded that CSF influx was occurring into the brain within minutes of tracer administration $[2,8,45,52]$.

In sum, our data support the conclusion that a bulk flow of CSF into the brain along the PVS likely does not occur under physiological conditions and that the rate of outflow of CSF is a major factor determining whether substances within CSF can spread to the brain. This work may have important implications in drug delivery to the CNS after intrathecal administration and in several conditions that may lead to altered CSF flow dynamics such as traumatic brain injury and stroke.

Acknowledgements Special thanks to Dr. Anna Polomska for preparation of the tracers, Prof. Markus Rudin for cantonal-approved access to animal license, Prof. Cornelia Halin for use of isoflurane equipment and Carlos Ochoa for excellent technical assistance. The authors also thank Prof. Dr. Michael D. Menger for support of the MRI facility, Dr. Yang Liu for breeding the wild type mice and Dr. Monika Frings for her help and guidance with the application for approval of animal experiments performed in Homburg. This work was supported by the Synapsis Foundation and the Heidi Seiler-Stiftung.

Author contributions QM, MR and STP conceived and designed the study; YD and AM designed and performed the MRI experiments; QM and STP performed the anesthesia versus awake experiments; MR, CR and STP performed the in vivo through-skull imaging and tracer influx after death experiments; QM, MR, CR, YD, AM and STP analyzed the data; QM, MR, MD, YD, AM and STP drafted the manuscript. All authors have approved the final version of the manuscript and have agreed to be accountable for all aspects of the work.

\section{Compliance with ethical standards}

Conflict of interest The authors declare no competing financial interests.

Open Access This article is distributed under the terms of the Creative Commons Attribution 4.0 International License (http://creativeco mmons.org/licenses/by/4.0/), which permits unrestricted use, distribution, and reproduction in any medium, provided you give appropriate credit to the original author(s) and the source, provide a link to the Creative Commons license, and indicate if changes were made.

\section{References}

1. Abbott NJ, Pizzo ME, Preston JE, Janigro D, Thorne RG (2018) The role of brain barriers in fluid movement in the CNS: is there a 'glymphatic' system? Acta Neuropathol 135:387-407. https:// doi.org/10.1007/s00401-018-1812-4

2. Albargothy NJ, Johnston DA, MacGregor-Sharp M, Weller RO, Verma A, Hawkes CA, Carare RO (2018) Convective influx/glymphatic system: tracers injected into the CSF enter and leave the brain along separate periarterial basement membrane pathways. Acta Neuropathol 136:139-152. https://doi.org/10.1007/s0040 1-018-1862-7

3. Asgari M, de Zelicourt D, Kurtcuoglu V (2016) Glymphatic solute transport does not require bulk flow. Sci Rep 6:38635. https://doi. org/10.1038/srep38635

4. Aspelund A, Antila S, Proulx ST, Karlsen TV, Karaman S, Detmar M, Wiig H, Alitalo K (2015) A dural lymphatic vascular system that drains brain interstitial fluid and macromolecules. J Exp Med 212:991-999. https://doi.org/10.1084/jem.20142290

5. Bakker EN, Bacskai BJ, Arbel-Ornath M, Aldea R, Bedussi B, Morris AW, Weller RO, Carare RO (2016) Lymphatic clearance of the brain: perivascular, paravascular and significance for neurodegenerative diseases. Cell Mol Neurobiol 36:181-194. https:// doi.org/10.1007/s10571-015-0273-8

6. Bedussi B, Almasian M, de Vos J, VanBavel E, Bakker EN (2018) Paravascular spaces at the brain surface: low resistance pathways 
for cerebrospinal fluid flow. J Cereb Blood Flow Metab 38:719726. https://doi.org/10.1177/0271678X17737984

7. Benveniste H, Lee H, Ding F, Sun Q, Al-Bizri E, Makaryus R, Probst S, Nedergaard M, Stein EA, Lu H (2017) Anesthesia with dexmedetomidine and low-dose isoflurane increases solute transport via the glymphatic pathway in rat brain when compared with high-dose isoflurane. Anesthesiology 127:976-988. https://doi. org/10.1097/ALN.0000000000001888

8. Borison HL, Borison R, Mccarthy LE (1980) Brain-stem penetration by horseradish-peroxidase from the cerebrospinal-fluid spaces in the cat. Exp Neurol 69:271-289

9. Boulton M, Armstrong D, Flessner M, Hay J, Szalai JP, Johnston M (1998) Raised intracranial pressure increases CSF drainage through arachnoid villi and extracranial lymphatics. Am J Physiol 275:R889-R896

10. Bradbury MWB, Cserr HF (1985) Drainage of cerebral interstitial fluid and of cerebrospinal fluid into lymphatics. In: Johnston MG (ed) Experimental biology of the lymphatic circulation. Elsevier, Amsterdam, pp 355-394

11. Brierley JB (1950) The penetration of particulate matter from the cerebrospinal fluid into the spinal ganglia, peripheral nerves, and perivascular spaces of the central nervous system. J Neurol Neurosurg Psychiatry 13:203-215

12. Choi I, Chung HK, Ramu S, Lee HN, Kim KE, Lee S, Yoo J, Choi D, Lee YS, Aguilar B et al (2011) Visualization of lymphatic vessels by Prox1-promoter directed GFP reporter in a bacterial artificial chromosome-based transgenic mouse. Blood 117:362-365. https://doi.org/10.1182/blood-2010-07-298562

13. Cserr HF, Cooper DN, Milhorat TH (1977) Flow of cerebral interstitial fluid as indicated by the removal of extracellular markers from rat caudate nucleus. Exp Eye Res 25(Suppl):461-473

14. Davson H, Segal MB (1996) Physiology of the CSF and bloodbrain barriers. CRC Press, Boca Raton

15. Dobson H, Sharp MM, Cumpsty R, Criswell TP, Wellman T, Finucane C, Sullivan JM, Weller RO, Verma A, Carare RO (2017) The perivascular pathways for influx of cerebrospinal fluid are most efficient in the midbrain. Clin Sci (Lond) 131:2745-2752. https://doi.org/10.1042/CS20171265

16. Dreha-Kulaczewski S, Joseph AA, Merboldt KD, Ludwig HC, Gartner J, Frahm J (2015) Inspiration is the major regulator of human CSF flow. J Neurosci 35:2485-2491. https://doi. org/10.1523/JNEUROSCI.3246-14.2015

17. Edsbagge M, Tisell M, Jacobsson L, Wikkelso C (2004) Spinal CSF absorption in healthy individuals. Am J Physiol Regul Integr Comp Physiol 287:R1450-R1455. https://doi.org/10.1152/ajpre gu.00215.2004

18. Engelhardt B, Carare RO, Bechmann I, Flugel A, Laman JD, Weller RO (2016) Vascular, glial, and lymphatic immune gateways of the central nervous system. Acta Neuropathol 132:317338. https://doi.org/10.1007/s00401-016-1606-5

19. Faghih MM, Sharp MK (2018) Is bulk flow plausible in perivascular, paravascular and paravenous channels? Fluids Barriers CNS 15:17. https://doi.org/10.1186/s12987-018-0103-8

20. Fishman RA (1992) Cerebrospinal fluid in diseases of the nervous system. Saunders, Philadelphia

21. Gakuba C, Gaberel T, Goursaud S, Bourges J, Di Palma C, Quenault A, de Lizarrondo SM, Vivien D, Gauberti M (2018) General anesthesia inhibits the activity of the "glymphatic system". Theranostics 8:710-722. https://doi.org/10.7150/thno.19154

22. Hall JG, Morris B, Woolley G (1965) Intrinsic rhythmic propulsion of lymph in the unanaesthetized sheep. J Physiol 180:336-349

23. Heisey SR, Held D, Pappenheimer JR (1962) Bulk flow and diffusion in the cerebrospinal fluid system of the goat. Am J Physiol 203:775-781. https://doi.org/10.1152/ajplegacy.1962.203.5.775
24. His W (1865) Über ein Perivasculäres Canalsystem in den Nervösen Centralorganen. Wilhelm Engelmann, Leipzig

25. Hladky SB, Barrand MA (2014) Mechanisms of fluid movement into, through and out of the brain: evaluation of the evidence. Fluids Barriers CNS 11:26. https://doi.org/10.1186/2045-8118-11-26

26. Holter KE, Kehlet B, Devor A, Sejnowski TJ, Dale AM, Omholt SW, Ottersen OP, Nagelhus EA, Mardal KA, Pettersen KH (2017) Interstitial solute transport in 3D reconstructed neuropil occurs by diffusion rather than bulk flow. Proc Natl Acad Sci USA 114:9894-9899. https://doi.org/10.1073/pnas.1706942114

27. Ichimura T, Fraser PA, Cserr HF (1991) Distribution of extracellular tracers in perivascular spaces of the rat brain. Brain Res 545:103-113

28. Iliff JJ, Goldman SA, Nedergaard M (2015) Implications of the discovery of brain lymphatic pathways. Lancet Neurol 14:977979. https://doi.org/10.1016/S1474-4422(15)00221-5

29. Iliff JJ, Wang M, Liao Y, Plogg BA, Peng W, Gundersen GA, Benveniste H, Vates GE, Deane R, Goldman SA et al (2012) A paravascular pathway facilitates CSF flow through the brain parenchyma and the clearance of interstitial solutes, including amyloid beta. Sci Transl Med 4:147ra111. https://doi.org/10.1126/ scitranslmed. 3003748

30. Ineichen BV, Schnell L, Gullo M, Kaiser J, Schneider MP, Mosberger AC, Good N, Linnebank M, Schwab ME (2017) Direct, long-term intrathecal application of therapeutics to the rodent CNS. Nat Protoc 12:104-131. https://doi.org/10.1038/nprot .2016.151

31. Johnston M, Zakharov A, Papaiconomou C, Salmasi G, Armstrong D (2004) Evidence of connections between cerebrospinal fluid and nasal lymphatic vessels in humans, non-human primates and other mammalian species. Cerebrospinal Fluid Res 1:2. https ://doi.org/10.1186/1743-8454-1-2

32. Kida S, Pantazis A, Weller RO (1993) CSF drains directly from the subarachnoid space into nasal lymphatics in the rat. Anatomy, histology and immunological significance. Neuropathol Appl Neurobiol 19:480-488

33. Koh L, Zakharov A, Johnston M (2005) Integration of the subarachnoid space and lymphatics: is it time to embrace a new concept of cerebrospinal fluid absorption? Cereb Fluid Res 2:6. https ://doi.org/10.1186/1743-8454-2-6

34. Lee H, Mortensen K, Sanggaard S, Koch P, Brunner H, Quistorff B, Nedergaard M, Benveniste H (2018) Quantitative GdDOTA uptake from cerebrospinal fluid into rat brain using 3D VFA-SPGR at 9.4T. Magn Reson Med 79:1568-1578. https://doi. org $/ 10.1002 / \mathrm{mrm} .26779$

35. Louveau A, Plog BA, Antila S, Alitalo K, Nedergaard M, Kipnis J (2017) Understanding the functions and relationships of the glymphatic system and meningeal lymphatics. J Clin Investig 127:3210-3219. https://doi.org/10.1172/JCI90603

36. Louveau A, Smirnov I, Keyes TJ, Eccles JD, Rouhani SJ, Peske JD, Derecki NC, Castle D, Mandell JW, Lee KS et al (2015) Structural and functional features of central nervous system lymphatic vessels. Nature 523:337-341. https://doi.org/10.1038/nature1443 2

37. Ma Q, Ineichen BV, Detmar M, Proulx ST (2017) Outflow of cerebrospinal fluid is predominantly through lymphatic vessels and is reduced in aged mice. Nat Commun 8:1434. https://doi. org/10.1038/s41467-017-01484-6

38. McComb JGHS, Weiss MH (1990) Lymphatic drainage of cerebrospinal fluid in the primate. In: Johansson BB, Owman C, Widner $\mathrm{H}$ (eds) Pathophysiology of the blood-brain barrier. Elsevier, Amsterdam, pp 421-438

39. McComb JG (1983) Recent research into the nature of cerebrospinal fluid formation and absorption. J Neurosurg 59:369-383. https://doi.org/10.3171/jns.1983.59.3.0369

40. Mott FW (1910) The cerebro-spinal fluid. Lancet 2:1-8 
41. Muller A, Fries P, Jelvani B, Lux F, Rube CE, Kremp S, Giovanoli P, Buecker A, Menger MD, Laschke MW et al (2017) Magnetic resonance lymphography at $9.4 \mathrm{~T}$ using a gadolinium-based nanoparticle in rats: investigations in healthy animals and in a hindlimb lymphedema model. Investig Radiol 52:725-733. https ://doi.org/10.1097/RLI.0000000000000398

42. Pizzo ME, Wolak DJ, Kumar NN, Brunette E, Brunnquell CL, Hannocks MJ, Abbott NJ, Meyerand ME, Sorokin L, Stanimirovic DB et al (2018) Intrathecal antibody distribution in the rat brain: surface diffusion, perivascular transport and osmotic enhancement of delivery. J Physiol 596:445-475. https://doi.org/10.1113/JP275 105

43. Proulx ST, Luciani P, Christiansen A, Karaman S, Blum KS, Rinderknecht M, Leroux JC, Detmar M (2013) Use of a PEGconjugated bright near-infrared dye for functional imaging of rerouting of tumor lymphatic drainage after sentinel lymph node metastasis. Biomaterials 34:5128-5137. https://doi.org/10.1016/j. biomaterials.2013.03.034

44. Proulx ST, Ma Q, Andina D, Leroux JC, Detmar M (2017) Quantitative measurement of lymphatic function in mice by noninvasive near-infrared imaging of a peripheral vein. JCI Insight. https://doi. org/10.1172/jci.insight.90861

45. Rennels ML, Gregory TF, Blaumanis OR, Fujimoto K, Grady PA (1985) Evidence for a 'paravascular' fluid circulation in the mammalian central nervous system, provided by the rapid distribution of tracer protein throughout the brain from the subarachnoid space. Brain Res 326:47-63

46. Reulen HJ, Tsuyumu M, Tack A, Fenske AR, Prioleau GR (1978) Clearance of edema fluid into cerebrospinal fluid. A mechanism for resolution of vasogenic brain edema. J Neurosurg 48:754-764. https://doi.org/10.3171/jns.1978.48.5.0754

47. Ringstad G, Vatnehol SAS, Eide PK (2017) Glymphatic MRI in idiopathic normal pressure hydrocephalus. Brain 140:2691-2705. https://doi.org/10.1093/brain/awx191

48. Rosenberg GA, Kyner WT, Estrada E (1980) Bulk flow of brain interstitial fluid under normal and hyperosmolar conditions.
Am J Physiol 238:F42-F49. https://doi.org/10.1152/ajpre nal.1980.238.1.F42

49. Schad H, Brechtelsbauer H (1977) Thoracic duct lymph flow and composition in conscious dogs and the influence of anaesthesia and passive limb movement. Pflugers Arch 371:25-31

50. Smith AJ, Yao X, Dix JA, Jin BJ, Verkman AS (2017) Test of the 'glymphatic' hypothesis demonstrates diffusive and aquaporin4-independent solute transport in rodent brain parenchyma. Elife. https://doi.org/10.7554/eLife.27679

51. Spector R, Robert Snodgrass S, Johanson CE (2015) A balanced view of the cerebrospinal fluid composition and functions: focus on adult humans. Exp Neurol 273:57-68. https://doi. org/10.1016/j.expneurol.2015.07.027

52. Wagner HJ, Pilgrim C, Brandl J (1974) Penetration and removal of horseradish peroxidase injected into the cerebrospinal fluid: role of cerebral perivascular spaces, endothelium and microglia. Acta Neuropathol 27:299-315

53. Weed LH (1914) Studies on cerebro-spinal fluid. no. IV: the dual source of cerebro-spinal fluid. J Med Res 31:93-118 (111)

54. Xie L, Kang H, Xu Q, Chen MJ, Liao Y, Thiyagarajan M, O’Donnell J, Christensen DJ, Nicholson C, Iliff JJ et al (2013) Sleep drives metabolite clearance from the adult brain. Science 342:373-377. https://doi.org/10.1126/science.1241224

55. Xin HB, Deng KY, Rishniw M, Ji G, Kotlikoff MI (2002) Smooth muscle expression of Cre recombinase and eGFP in transgenic mice. Physiol Genom 10:211-215. https://doi.org/10.1152/physi olgenomics.00054.2002

56. Zervas NT, Liszczak TM, Mayberg MR, Black PM (1982) Cerebrospinal fluid may nourish cerebral vessels through pathways in the adventitia that may be analogous to systemic vasa vasorum. J Neurosurg 56:475-481. https://doi.org/10.3171/ jns.1982.56.4.0475

57. Zhang ET, Richards HK, Kida S, Weller RO (1992) Directional and compartmentalised drainage of interstitial fluid and cerebrospinal fluid from the rat brain. Acta Neuropathol 83:233-239 